Check for updates

Cite this: RSC Adv., 2017, 7, 23515

Received 3rd March 2017 Accepted 11th April 2017

DOI: $10.1039 / \mathrm{c} 7 \mathrm{ra02638b}$

rsc.li/rsc-advances

\title{
Combination of $\mathrm{RuCl}_{3} \cdot x \mathrm{H}_{2} \mathrm{O}$ with PEG - a simple and recyclable catalytic system for direct arylation of heteroarenes via $\mathrm{C}-\mathrm{H}$ bond activation $\dagger$
}

\author{
Lei Jian, Hai-Yu He, Jin Huang, Qian-Hui Wu, Mao-Lin Yuan, ${ }^{*}$ Hai-Yan Fu, \\ Xue-Li Zheng, (D) Hua Chen and Rui-Xiang Li $\mathbb{D}$ *
}

\begin{abstract}
A simple and recyclable catalytic system for direct arylation of heteroarenes via $\mathrm{C}-\mathrm{H}$ bond activation was developed with a relatively inexpensive $\mathrm{RuCl}_{3} \cdot \mathrm{HH}_{2} \mathrm{O}$ as a catalyst and $\mathrm{PEG}-400$ as a green medium without any additive or ligand. This system not only showed excellent functional group compatibility, but also the ratio of mono- to diarylated product was easily regulated by varying the reaction conditions. Moreover, this transformation could proceed under air and be easily scaled up to gram-scale in a low catalyst loading of $0.3 \mathrm{~mol} \%$. Particularly, a good yield of $85 \%$ was obtained after this catalyst was recycled six times.
\end{abstract}

\section{Introduction}

In recent years, N-heteroaromatic scaffolds are becoming an increasing necessity, due to the structural motifs for a wide range applications in pharmaceuticals, natural products, functional materials ${ }^{1}$ and ligands for highly efficient and selective catalysis. ${ }^{2}$ Thus, there is an important need to develop an efficient synthetic methodology to make up the building blocks. Although transition metal catalyzed cross-coupling reaction of aryl halides with organometallic reagents to synthesize a series of heterocyclic compounds has matured to being a reliable tool, ${ }^{3}$ catalytic direct arylation via activation of $\mathrm{C}-\mathrm{H}$ bond still garners tremendous interest due to obviating prefunctionalization, ${ }^{4,5}$ which addresses the issues on prolix steps of organic synthesis, formation of undesired side-product and use of auxiliary chemicals. Nevertheless, transition-metal-complexes catalyzed direct arylation via $\mathrm{C}-\mathrm{H}$ activation still confronts various challenges. The preparation of complexes suffers from a tedious synthesis process and they are difficult to be recycled after reaction. For direct arylation in heterogeneous catalysis, polymer supported metal catalysts, such as PVP supported Pdnanoparticle, ${ }^{6 a} \operatorname{Pd}(\mathrm{II}) @ m i c r o p o r o u s ~$ polymers $^{6 b}$ and heterogenization of homogeneous catalysts, such as polystyrenesupported palladium complex, ${ }^{6 c}$ polymer-supported pyridine$\mathrm{Pd}^{6 d}$ poly(ethyleneglycol)-bound SCS-Pd complexes ${ }^{6 e}$ and MOP$\mathrm{PPh}_{3}-\mathrm{Pd}^{6 f}$ seem to be extremely effective ways to accomplish the

Key Lab of Green Chemistry and Technology, Ministry of Education, College of Chemistry, Sichuan University, Chengdu 610064, People's Republic of China. E-mail: liruixiang@scu.edu.cn; Fax: +86-28-8541-2904

$\dagger$ Electronic supplementary information (ESI) available. CCDC 1481843. For ESI and crystallographic data in CIF or other electronic format see DOI: $10.1039 / \mathrm{c} 7 \mathrm{ra02638b}$ separation and recycling of the catalysts. To date, the preparation of these catalysts is not easy and leaching of metals cannot be inhibited completely. In addition, NMP or toluene as solvent ${ }^{7}$ is highly toxic and is usually classified to be detrimental to the environment. To meet the requirements of green chemistry, some eco-friendly solvents such as CPME, 2-MeTHF and dialkyl carbonates have been chosen as the reaction media in direct arylation. ${ }^{8}$ Although water is a better alternative, the metal complex as a catalyst must be water-soluble and insensitive to water. ${ }^{9}$

Polyethylene glycol has been the perfect reaction media, which offers a suitable strategy to meet the requirement of green chemistry. ${ }^{10}$ To date, several successful examples have been reported using PEG as reaction medium, such as direct alkynylation of heteroarene, ${ }^{10 a}$ one-pot synthesis of propargylamines, aminoindolizine, 2,4,6-triaryl-pyridines, piperidines, and 3,4-dihydro-pyrimidinones, ${ }^{10 b-f}$ oxidative coupling of 2arylbenzimidazoles with alkynes ${ }^{10 g}$ and hydroxylation of 2-arylpyridine. ${ }^{10 h}$ However, ruthenium catalyzed direct arylation in PEG, which was reported by Ackermann et al. ${ }^{11 a}$ and Hiebel et al. ${ }^{11 b}$ under nitrogen atmosphere gave the arylated products with a moderate yield but in air it was inactive. ${ }^{11 a}$ In addition, most of the catalytic systems for direct arylation are required to be performed in oxygen-free conditions. ${ }^{12}$ Hence, to develop a simple and sustainable method was highly desirable with green chemistry into consideration. Herein, in continuation to our earlier studies on developing improved methodologies for direct arylation, ${ }^{16}$ we propose a simple and recyclable catalytic system for direct arylation of heteroarenes by employing $\mathrm{RuCl}_{3} \cdot x \mathrm{H}_{2} \mathrm{O}$ as the catalyst, inexpensive aryl chlorides as the arylating reagents and PEG-400 as the "green" reaction medium without any additives or ligands. The strategy that was accomplished in air gave a satisfactory yield and a relatively high 
selectivity. Particularly, the ratio of mono- to diarylated product was easily regulated by varying the reaction conditions.

\section{Results and discussion}

\subsection{Effect of the reaction conditions}

In initial investigation, the model reaction of 2-phenylpyridine 1a (1 mmol) with coupling partner 1-chloro-3-fluorobenzene 2a (2.3 equiv.) was conducted in $1 \mathrm{~mL}$ PEG-400 to determine the optimum conditions. First, effect of various bases on this catalytic system was tested without any additive or ligand (Table 1 ). In the beginning, CsF, $\mathrm{K}_{3} \mathrm{PO}_{4}, \mathrm{~K}_{2} \mathrm{CO}_{3}, \mathrm{NaHCO}_{3}, \mathrm{Na}_{2} \mathrm{SO}_{3}$ and EtONa were substantially less effective on the transformation (Table 1, entries 1-6). Interestingly, when $\mathrm{CH}_{3} \mathrm{COOK}$ was applied in the system under similar conditions, an excellent yield of $94 \%$ for target products 3aa and 4aa, and relatively high selectivity towards monoarylation were obtained in $1 \mathrm{~h}$ (Table 1, entry 7-II). However, prolonging the reaction time resulted in a decrease of monoarylated product 3aa (Table 1, entries 7-IV and 7-VI), which was mainly attributed to the formation of dehydrogenative crosscoupling products 5aa, 6aa, 7aa. Interestingly, this system also afforded the target products 3aa and 4aa in the yield of $82 \%$ even if the reaction time was shortened to $15 \mathrm{~min}$ (Table 1, entry 7-I). To the best of our knowledge, the activity of this transformation was unprecedented. Among the reported cases, ${ }^{7}$ to obtain a satisfactory yield for direct arylation, the reaction time was at least 60 minutes, ${ }^{7 a}$ usually $20-40$ hours ${ }^{7 b-e}$ under similar conditions. The ratio of monoarylation to diarylation was further improved to 5.3/ 1 when 1a/2a was adjusted to 1.2/1 (see ESI $\dagger$ ). Compared with $\mathrm{CH}_{3} \mathrm{COOK}, \mathrm{CH}_{3} \mathrm{COONa}$ as a base also displayed similar activity and selectivity (Table 1, entry 8). Furthermore, it was notable that $\mathrm{LiOH} \cdot \mathrm{H}_{2} \mathrm{O}$ (3 equiv.) afforded a high yield of $98 \%$ and proved highly efficient to form diarylated product 4aa (Table 1, entries 9II and 9-III). Apart from $\mathrm{LiOH} \cdot \mathrm{H}_{2} \mathrm{O}$, the introduction of $\mathrm{KOH}$, $\mathrm{NaOH}, \mathrm{CsOH}, \mathrm{Li}_{2} \mathrm{CO}_{3}$, and $t$-BuOLi resulted in discontented yields (Table 1, entries 10-14). Considering the promotional effect of $\mathrm{Li}^{+}$ and $\mathrm{CH}_{3} \mathrm{COO}^{-}$on the reaction, we were motivated to probe the role of $\mathrm{CH}_{3} \mathrm{COOLi}$ in the reaction. However, it gave the target products with a moderate yield of $50 \%$ (Table 1 , entry 15). $\mathrm{NEt}_{3}$ was also a good base in this transformation, but it was unfavorable to improve the selectivity towards monoarylated or diarylated product (Table 1, entry 16). In the absence of a base, almost no target products were obtained, and only oligomerization products 8, 9 and 10 were observed in this process, highlighting the importance of a base for the direct arylation process (Table 1, entry 17) (Fig. 1). Based on the above findings, it was clearly indicated that the system took advantage of high reactivity and easily regulated the ratio of diarylated to monoarylated product. The diarylation was facilitated using $5 \mathrm{~mol} \% \mathrm{RuCl}_{3} \cdot x \mathrm{H}_{2} \mathrm{O}$ as a catalyst and 3 equiv. $\mathrm{LiOH} \cdot \mathrm{H}_{2} \mathrm{O}$ as a base at $120{ }^{\circ} \mathrm{C}$ for $24 \mathrm{~h}$. Intriguingly, the system strongly favoured the monoarylation just by switching the base to $\mathrm{CH}_{3} \mathrm{COOK}$ and shortened the reaction time to $1 \mathrm{~h}$. In this reaction process, the hydroxyl group of PEG400 played the role of a reductant for the precatalyst $\mathrm{RuCl}_{3} \cdot x \mathrm{H}_{2} \mathrm{O} .{ }^{13}$

The further solvent screening indicated that target products could not be generated in toluene or water (Table 1, entry 18-I). It
Table 1 Effect of reaction conditions on arylation of 2-phenylpyridine with 1-chloro-3-fluorobenzene ${ }^{a}$

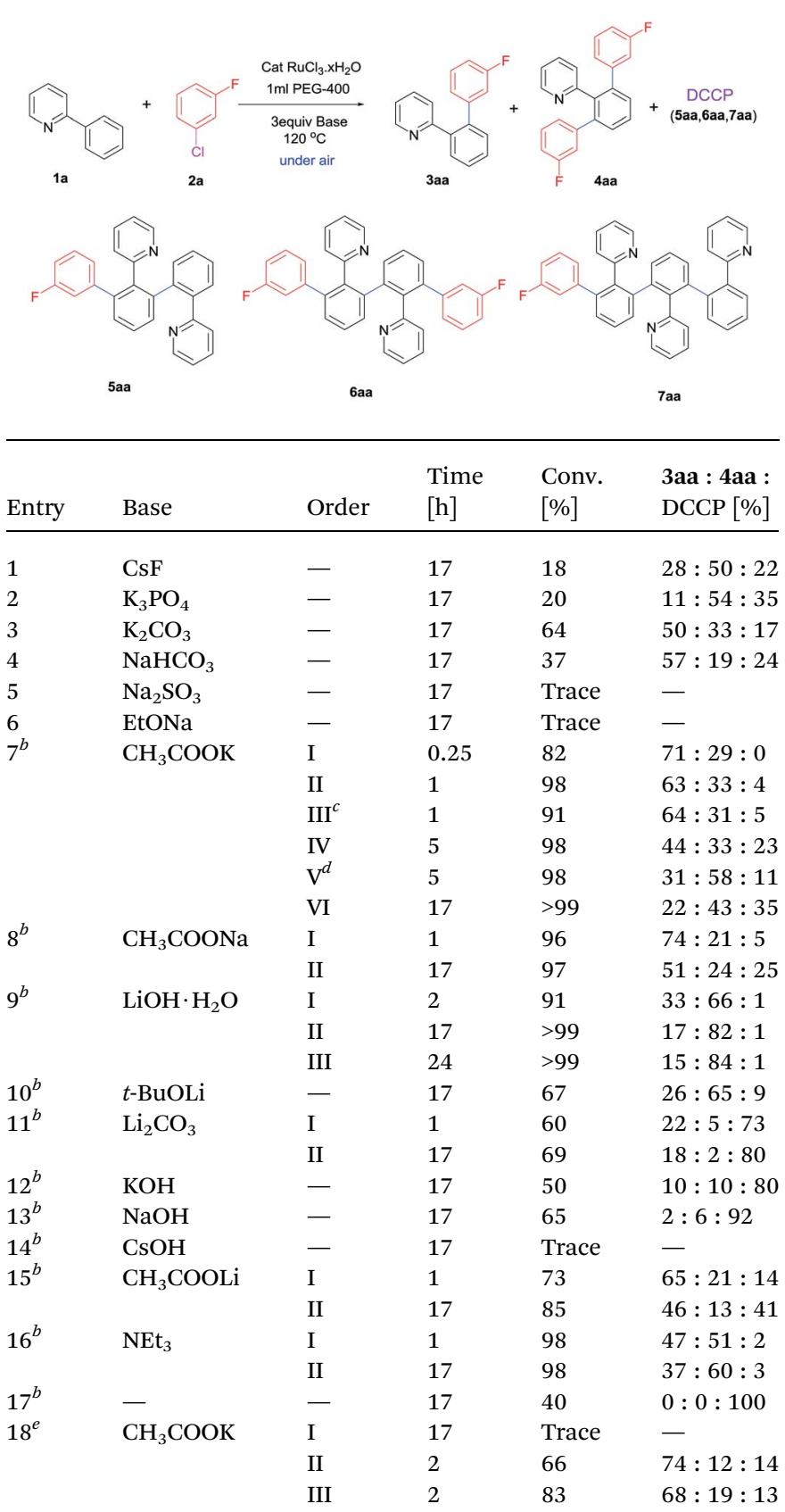

${ }^{a}$ 2-Phenylpyridine (1 mmol), 3-fluoro-chlorobenzene (2.3 mmol), PEG$400(1 \mathrm{~mL}), \mathrm{RuCl}_{3} \cdot x \mathrm{H}_{2} \mathrm{O}(5 \mathrm{~mol} \%)$, and base (3 equiv.), $120^{\circ} \mathrm{C}$, under air. Yield was isolated yield. ${ }^{b}$ (Entries 7-17) Yield and ratio of the mono- and diarylated products were determined by HPLC. ${ }^{c}(3 \mathrm{~mol} \%)$ $\mathrm{RuCl}_{3} \cdot x \mathrm{H}_{2} \mathrm{O} .{ }^{d}$ Adding 3 -fluoro-chlorobenzene (2.3 equiv.) again after $0.5 \mathrm{~h} .{ }^{e} \mathrm{I}$ - toluene, water or $\mathrm{MeOH}$ as solvent; II - ethylene glycol as solvent; III - ethylene glycol as solvent and adding 18-crown-6 (1 $\mathrm{mmol}$ ) to the reaction system.

was found that a moderate yield of $57 \%$ was also obtained in ethylene glycol, but the direct arylation proved to be ineffective in $\mathrm{MeOH}$ as its low boiling point led to a low reaction temperature (Table 1, entries 18-I and 18-II). Compared to ethylene glycol, PEG 


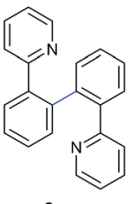

8

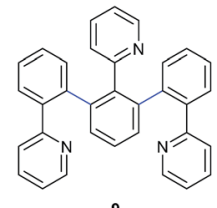

9

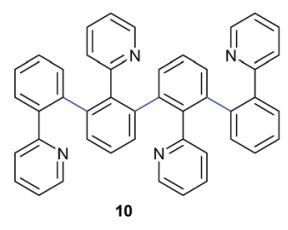

Fig. 1 The oligomerizations of 2-phenylpyridine.

Table 2 Effect of substrate to catalyst ratio on direct arylation of 2phenylpyridine with 1-chloro-3-fluorobenzene ${ }^{a}$

\begin{tabular}{lllll}
\hline Entry & S/C & Time $(\mathrm{h})$ & Yield [\%] & 3aa/4aa [\%] \\
\hline 1 & 20 & 1 & 90 & $77: 23$ \\
2 & 40 & 1 & 91 & $80: 20$ \\
3 & 160 & 1 & 89 & $81: 19$ \\
4 & 300 & 1 & 50 & $84: 16$ \\
& & 4 & 92 & $78: 22$ \\
5 & 600 & 10 & 32 & $82: 18$ \\
& & 24 & $34(40)$ & $80: 20$
\end{tabular}

${ }^{a}$ Reaction conditions: 2-phenylpyridine ( $n \mathrm{mmol}$ ), 3-fluoro-chlorobenzene $(n+0.3 \mathrm{mmol})$, PEG-400 as reaction medium $(1 \mathrm{~mL})$, $\mathrm{RuCl}_{3} \cdot x \mathrm{H}_{2} \mathrm{O}(0.05 \mathrm{mmol})$, and $\mathrm{CH}_{3} \mathrm{COOK}$ (2 equiv.) and the reaction mixture was heated to $120{ }^{\circ} \mathrm{C}$ under air. The yield and ratio of monoto diarylated product determined by HPLC.

was a better solvent. The weak interaction of PEG with ruthenium species might enhance the reactivity, analogous to the coordination of crown ether with ruthenium. In order to demonstrate it, 18-crown- 6 was added to ethylene glycol, and it was found that this transformation was siginificantly improved (Table 1, entry 18III). The above results suggested that the coordination of PEG with ruthenium, which was similar to the role of crown ether, promoted the performance of ruthenium in addition to the reduction role of hydroxyl group in PEG. Furthermore, the effect of reaction temperature indicated that a higher temperature of $150{ }^{\circ} \mathrm{C}$ resulted in more dehydrogenative cross-coupling products (DCCP) and a lower temperature of $90^{\circ} \mathrm{C}$ caused a decrease of the catalytic activity (see $\mathrm{ESI} \dagger$ ). The catalytic performance of this simple system under optimum conditions was comparable to NHC-ruthenium(II) complexes, ${ }^{14}$ phosphine-[ $\mathrm{RuCl}_{2}(p$-cymene $\left.)\right]_{2}{ }^{15}$ $\left[\mathrm{RuCl}_{2}\left(\eta^{6}\right.\right.$-benzene)MOTPP $]{ }^{16}$ and iridium-ruthenium bimetallic complexes bearing triazolediylidene. ${ }^{17}$

On taking catalyst loading into consideration, when the amount of ruthenium was decreased to $3 \mathrm{~mol} \%$, this system gave a satisfactory yield of $86 \%$ (Table 1 , entry 7 -III). Gratifying, we were surprised to find that this transformation could be easily scaled up to gram level with a comparable yield of $93 \%$ when $\mathrm{S} / \mathrm{C}$ was extended to $300 / 1$ for $4 \mathrm{~h}$ (Table 2 ).

\subsection{The scope of the proposed direct arylation and recyclability of the catalyst}

With optimum reaction conditions, we explored the scope of direct arylation protocol. It was found that this system was of wide substrate suitability. Moreover, diarylated derivatives of heteroarene were predominantly achieved by employing aryl chlorides as arylating reagents containing a variety of functional groups (Table 3). Overall, the reaction provided the desired products in high yields (77-99\%). It was important to note that direct arylation of 2-phenylpyridine proceeded with high efficiency under an ambient atmosphere, highlighting the user-friendly nature of the proposed protocol. Chlorobenzene $\mathbf{2 b}$ was used as arylating reagent to give an impressive yield of $92 \%$ (Table 3 , entry 1 ). Notably, all aryl chlorides with substituents derived from electronrich groups $\left(-\mathrm{OCH}_{3},-\mathrm{CH}_{3}\right)$ as well as electron-deficient groups $\left(-\mathrm{CF}_{3},-\mathrm{F},-\mathrm{COCH}_{3},-\mathrm{CN}\right)$ were converted into the desired products with high yields under the reaction conditions (Table 3, entries 3 , $4,6,7,9,10,12-15$ and 21). Those results clearly indicated that this system was insensitive to electronic factor. At the same time, heteroaryl chlorides were also surveyed to furnish the desired products with a comparably better yield (Table 3, entries 16-18). However, for aryl chlorides containing a substituent in orthoposition, they afforded arylated products with relatively low yields due to steric hindrance of ortho-substituent $^{9 e}$ (Table 3, entries 2, 5 and 11). However, for 1-chloro-2-fluoro-benzene and 3-chloropyridine (Table 3, entries 8 and 19), only a trace amount of product was obtained. Furthermore, 4-chloronitrobenzene also gave a trace amount of target products in accordance with the literature $^{9 e}$ (Table 3, entry 20). It was noteworthy that the use of (hetero)aryl chlorides bearing various electron-deficient or electron-rich groups resulted in relatively high selectivity towards diarylation in the presence of $\mathrm{LiOH} \cdot \mathrm{H}_{2} \mathrm{O}$ except for $2 \mathbf{n}, \mathbf{2 0}, \mathbf{2 q}, \mathbf{2 r}$. Even so, the relatively high yield of diarylated product was obtained with 3 equiv. $\mathrm{CH}_{3} \mathrm{COOK}$ as the base for $1 \mathrm{~h}$ (Table 3, entries 14, 15, 17 and 18). On using $\mathrm{LiOH}$ with $\mathrm{CH}_{3} \mathrm{COOK}$ (2 equiv.), high selectivity towards monoarylation was achieved (Table 3, entries 13, 15 and 18). To explore the versatility of this transformation, 1phenylpyrazole and 2-phenyl-2-oxazoline were also surveyed to afford the desired products in moderate yields of $72 \%$ and $57 \%$, respectively (Table 3, entries 22 and 23). Moreover, the results were comparable to catalytic systems generated from Rh(III) complex in the presence of $\mathrm{Ag}$ salts under nitrogen atmosphere ${ }^{5 b}$ and $\left[\mathrm{Ru}\left(\mathrm{O}_{2} \mathrm{CMes}\right)_{2}(p\right.$-cymene $\left.)\right]$ with $p$-TsCl ${ }^{5 f}$ for direct arylation of 1-phenylpyrazole and 2-phenyl-2-oxazoline. Moreover, 2-phenylpyridine derivatives bearing various substituents on the phenyl ring were well tolerated (Table 3, entries 24, 25, 27 and 28). Substrate 1f was almost completely converted to monoarylated product due to steric hindrance of the methyl group (Table 3, entry 26). The high selectivity towards monoarylation, being caused by the steric hindrance of methyl group, was similar to the reported results. ${ }^{7 b, 18}$

On the other hand, this system could be conveniently re-used (Table 4). A good yield of $85 \%$ was still obtained with decreased selectivity after the catalyst was recycled 6 times. To the best of our knowledge, this is the first successful example for arylation achieving both gram-scale preparation with a low catalyst loading of $0.3 \mathrm{~mol} \%$ and maintaining its high activity after several recycles.

\subsection{Mechanism of direct arylation}

It was reported that catalytically active species were palladium nanoparticles for palladium-catalyzed direct arylation in PEG. ${ }^{\mathbf{1 1 a}}$ In this case, the mercury poison experiment, ${ }^{19}$ being an efficient 
Table 3 Ruthenium-catalyzed ortho-arylation of heteroarenes with (hetero)aryl chlorides ${ }^{a}$

$$
\text { 每 }
$$

under air

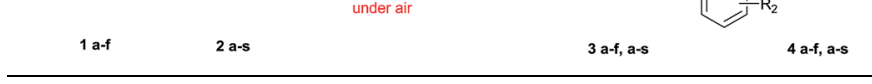

Entry Heteroarene

$$
\mathrm{ArCl}
$$

Yield (\%)

$3 / 4(\%)$<smiles>c1ccc(-c2ccccn2)cc1</smiles>

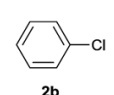

1

2<smiles>c1ccc(-c2ccccn2)cc1</smiles><smiles>c1ccc(-c2ccccn2)cc1</smiles><smiles>c1ccc(-c2ccccn2)cc1</smiles>

5<smiles>c1ccc(-c2ccccn2)cc1</smiles><smiles>c1ccc(-c2ccccn2)cc1</smiles><smiles>c1ccc(-c2ccccn2)cc1</smiles>

1a<smiles>c1ccc(-c2ccccn2)cc1</smiles><smiles>c1ccc(-c2ccccn2)cc1</smiles>

1a<smiles>c1ccc(-c2ccccn2)cc1</smiles>

10

11<smiles>c1ccc(-c2ccccn2)cc1</smiles>

12<smiles>c1ccc(-c2ccccn2)cc1</smiles>

13<smiles>c1ccc(-c2ccccn2)cc1</smiles><smiles>Cc1ccccc1Cl</smiles>

41<smiles>Cc1cccc(Cl)c1</smiles>

95<smiles>Cc1ccc(Cl)cc1</smiles><smiles>COc1ccccc1Cl</smiles>

44

92

84

77

90<smiles>COc1ccc(Cl)cc1</smiles>

${ }_{2 i}^{C-C(}$

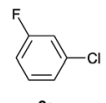

2a

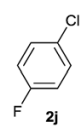

$-\mathrm{Cl}$

$2 \mathrm{k}$

$-\mathrm{Cl}$

2I

$\sum_{2 \mathrm{~m}}^{\mathrm{CF}_{3}}$

95

88

34

94

90
$67^{c}$
$37: 63^{d}$

$28: 72^{d} \quad 16$

$39: 61 \quad 17$

$39: 61 \quad 18$

$30: 70 \quad 19$

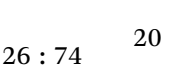

Trace $\quad-\quad 21$

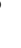

24

$30: 70 \quad 25$

$11: 89$

$73: 27$

26
$54: 46 \quad 15$

Table 3 (Contd.)

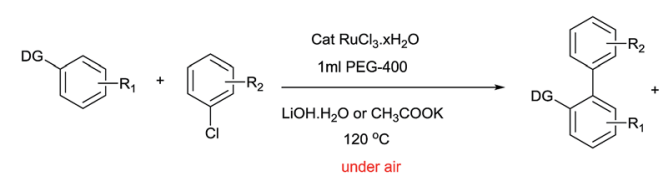

3 a-f, a-s

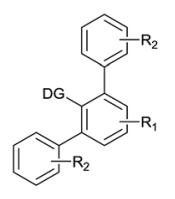

Yield (\%)

3/4 (\%)<smiles>c1ccc(-c2ccccn2)cc1</smiles>

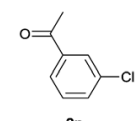

$92^{b}$

$58: 42$

14

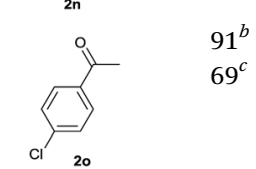

$2: 68$<smiles>c1ccc(-c2ccccn2)cc1</smiles><smiles>Clc1ccc2ccccc2n1</smiles>

$51: 49$<smiles>c1ccc(-c2ccccn2)cc1</smiles>

$\prod_{2 \mathrm{q}}^{\mathrm{S}}-\mathrm{Cl} \quad 288^{b}$

$75: 25$

$18: 82^{d}$<smiles>c1ccc(-c2ccccn2)cc1</smiles>

$\underbrace{s}_{2 r}$

36
$83^{b}$
$68^{c}$

$67: 33^{d}$

$31: 69^{d}$

1<smiles>Clc1cccnc1</smiles>

Trace<smiles>c1ccc(-c2ccccn2)cc1</smiles><smiles>c1ccc(-c2ccccn2)cc1</smiles><smiles>O=[N+]([O-])c1ccc(Cl)cc1</smiles>

Trace<smiles>c1ccc(-c2ccccn2)cc1</smiles><smiles>N#Cc1ccc(Cl)cc1</smiles>

$65^{b}$<smiles>c1ccc(-n2cccn2)cc1</smiles><smiles>FC(F)(F)c1ccc(Cl)cc1</smiles>

72<smiles>c1ccc(C2=NCCO2)cc1</smiles><smiles>FC(F)(F)c1ccc(Cl)cc1</smiles><smiles>COc1ccc(-c2ccccn2)cc1</smiles><smiles>FC(F)(F)c1ccc(Cl)cc1</smiles>

92

84<smiles>FC(F)(F)c1ccc(-c2ccccn2)cc1</smiles><smiles>FC(F)(F)c1ccc(Cl)cc1</smiles>

80

$95: 5$

$100: 0$<smiles>Cc1cccnc1-c1ccccc1</smiles><smiles>FC(F)(F)c1ccc(Cl)cc1</smiles> 
Table 3 (Contd.)

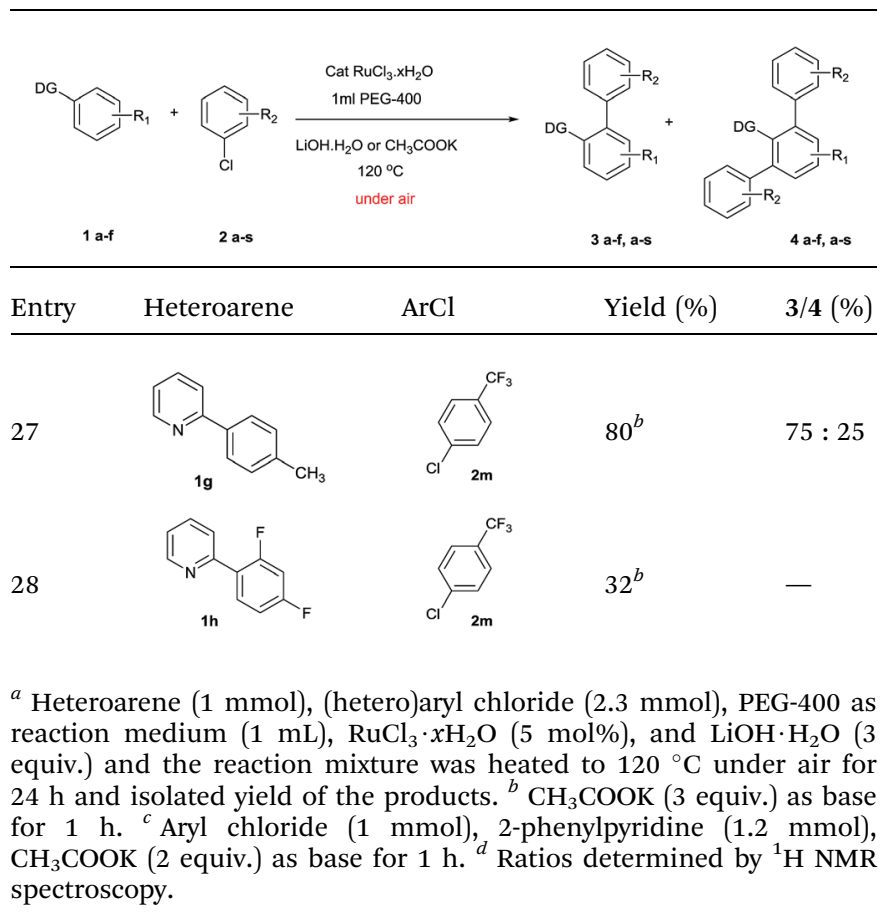

Table 4 Recyclability of the catalyst for direct arylation of 2-phenylpyridine with 1-chloro-3-fluorobenzene ${ }^{a}$

\begin{tabular}{lllll}
\hline Entry & Run & Time $[\mathrm{h}]$ & Yield $[\%]$ & Ratio (3aa/4aa) \\
\hline 1 & 1 & 5 & 94 & $22: 78$ \\
2 & 2 & 5 & 85 & $23: 77$ \\
3 & 3 & 12 & 93 & $30: 70$ \\
4 & 4 & 12 & 94 & $37: 63$ \\
5 & 5 & 12 & 81 & $57: 43$ \\
6 & 6 & 24 & 85 & $64: 36$
\end{tabular}

${ }^{a}$ Reaction conditions: 2-phenylpyridine (1 mmol), 3-fluoro-chlorobenzene $(2.3 \mathrm{mmol})$, PEG-400 as reaction medium $(1 \mathrm{~mL})$, $\mathrm{RuCl}_{3} \cdot x \mathrm{H}_{2} \mathrm{O}(5 \mathrm{~mol}-\%), \mathrm{LiOH} \cdot \mathrm{H}_{2} \mathrm{O}$ (3 equiv.), $120{ }^{\circ} \mathrm{C}$, and under air. The ratio of mono- to diarylation product was determined by HPLC. Equivalent base needed to be added in every recycling.

method to distinguish nanoparticle catalysis and homogeneous catalysis, showed that the activity of this catalytic system did not have any loss. The result proved that the catalytically active species were not ruthenium nanoparticles. Both experimental studies and density functional theory (DFT) calculations on ruthenium or palladium catalyzed direct arylation of heteroarene via $\mathrm{C}-\mathrm{H}$ activation have proposed that the reaction progressed via path 1 or path 2 (Scheme 1 ). ${ }^{20-22}$ In both paths, formation of cyclometalated ruthenium intermediate $\mathbf{C}$ was a key step. The intermediate $\mathbf{C}$ reacted with chlorobenzene via oxidative addition/reductive elimination sequence to give target products or 2-arylpyridine through the similar ortho-cyclometallated process to afford dehydrogenative cross-coupling products. Therefore, path 1 and path 2 were competitive

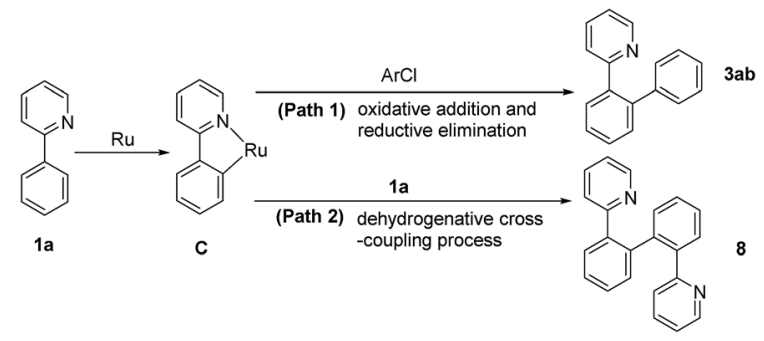

Scheme 1 Two competitive paths for arylation of 2-phenylpyridine.

routes in this transformation. In the proposed catalytic system, apart from the desired products 3aa and 4aa, formation of byproduct DCCP revealed that the reaction routes were in good agreement with the reported results. ${ }^{21}$

When $\mathrm{CH}_{3} \mathrm{COOK}$ was employed as the base, the reaction proceeded preferentially in path 1 (Table 1, entries 7-I and 7-II) and no DCCP was observed at the beginning of the reaction. If the reaction time was prolonged to $5 \mathrm{~h}$, the expended monoarylated product 3aa was almost completely transferred to DCCP (Table 1, entry 7-IV). This possibly resulted from the decrease in the chlorobenzene concentration, which slowed its oxidative addition rate with cyclometalated ruthenium intermediate. Moreover, the accumulated 3aa would promoted the formation of DCCP. It was thought that extra 1-chloro-3fluorobenzene (2.3 equiv.) was introduced into the system after the reaction began for $0.5 \mathrm{~h}$; the yield of diarylated product 4aa was significantly improved and dehydrogenation crossingcoupling processes were greatly inhibited (Table 1, entry 7-V). The result indicated that high concentration chlorobenzene was beneficial to direct the arylated reaction in path 1 . Based on concerted-metalation-deprotonation mechanism (CMD) with the assistance of carboxylate, ${ }^{22}$ a mechanism in the presence of potassium acetate was proposed in Scheme 2. First, Ru(III) species was reduced to $\mathrm{Ru}(\mathrm{II})$ by hydroxyl group in PEG-400. Moreover, the electron density of Ru was increased due to the weakly coordinated effect of PEG with $\mathrm{Ru}$, which resulted in enhancing the reactivity, similar to the role of a ligand. The reaction began with the cyclometalation of 2-phenylpyridine 1a to form intermediate $\mathbf{C}$ through acetate-assisted dehydrogenation process. Subsequently, intermediate $\mathbf{C}$ reacted with chlorobenzene $\mathbf{2 b}$ involving an oxidative-addition process to generate intermediate $\mathbf{D}$, which progressed by reduction elimination to give the monoarylated product $\mathbf{3 a b}$ and active ruthenium species $\mathbf{A}$. When most of $\mathbf{2 b}$ was used up, intermediate $\mathbf{C}$ easily reacted with $\mathbf{3 a b}$ or $\mathbf{1 a}$ to afford DCCP. Monoarylated product $\mathbf{3 a b}$ could also undergo the similar process to give the corresponding diarylated product and DCCP.

When the reaction was conducted with $\mathrm{LiOH}$, the rate of this reaction was dramatically decreased, but this system gave a relatively high selectivity to diarylated product and the formation of DCCP was greatly inhibited. It was suggested that the coordination of pyridyl group with $\mathrm{Li}^{+}$could slow the chelation-directed $\mathrm{C}-\mathrm{H}$ activation process. Based on the same reason, it also blocked the dehydrogenation cross-coupling route owing to a need to activate a second 2-phenylpyridine 


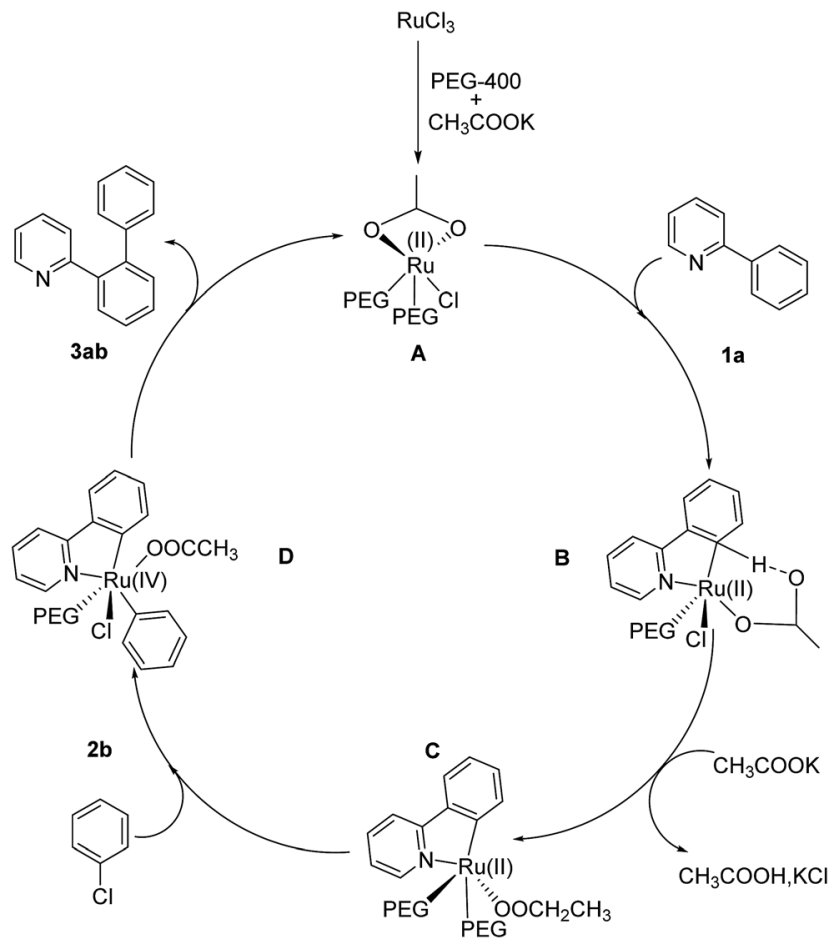

Scheme 2 Proposed mechanism for ruthenium-catalyzed direct arylation of 2-phenylpyridine.

$\mathrm{C}-\mathrm{H}$ bond by a chelation-directed process, but it did not affect oxidative addition with chlorobenzene. Consequently, the system with $\mathrm{LiOH}$ was not only in favour of diarylation, but also greatly inhibited the formation of DCCP. To obtain some experimental evidence, PEG-400 $(200 \mu \mathrm{L})$, 2-phenylpyridine (1 mmol) and $\mathrm{Li}^{+}(1 \mathrm{mmol})$ were added to a Schlenk tube and stirred under air at $120^{\circ} \mathrm{C}$ for $17 \mathrm{~h}$. Evidently, the coordination of the $\mathrm{Li}^{+}$with 2-phenylpyridine was clearly observed in both ${ }^{1} \mathrm{H}$ and ${ }^{13} \mathrm{C}$ NMR spectra (Fig. 2 and 3). For other lithium salts, $t$ BuOLi as base also strongly favors the diarylation of 2-phenylpyridine, analogous to the promotional role of LiOH (Table 1, entry 10). However, $\mathrm{Li}_{2} \mathrm{CO}_{3}$ or $\mathrm{CH}_{3} \mathrm{COOLi}$ as base showed a different result with $\mathrm{LiOH}$ and $t$-BuOLi (Table 1, entries 11 and

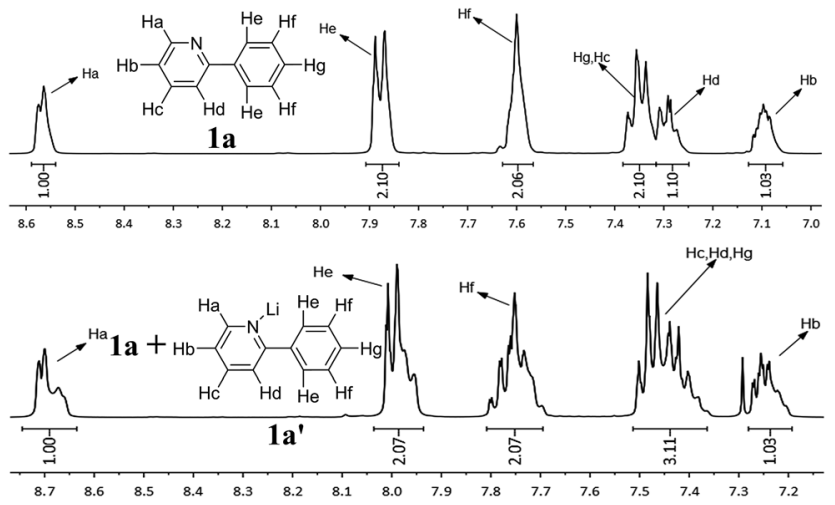

Fig. $2{ }^{1} \mathrm{H}$ NMR spectra for 2-phenylpyridine $1 \mathrm{a}$ in PEG and the mixture of 2-phenylpyridine and Li salt $1 a^{\prime}$ with $1 \mathrm{a}$ in PEG.

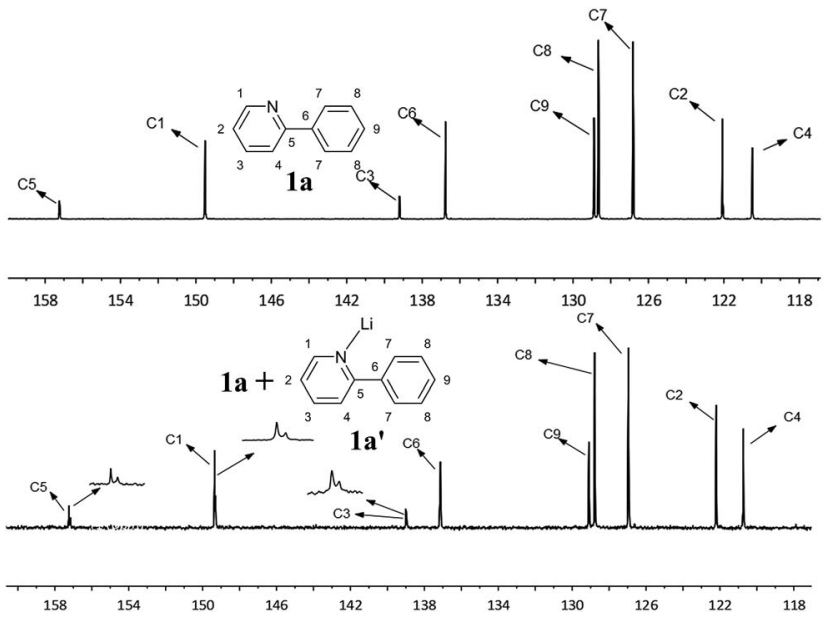

Fig. $3{ }^{13} \mathrm{C}$ NMR spectra for 2-phenylpyridine $1 \mathrm{a}$ in PEG and the mixture of 2-phenylpyridine and Li salt $1 a^{\prime}$ with $1 a$ in PEG.

15). The promotional mechanism of LiOH was not in agreement with the CMD mechanism. The reaction possibly proceeded by a chelation-directed $\mathrm{C}-\mathrm{H}$ activation with $\mathrm{OH}^{-}$to abstract proton to generate a cyclometalated ruthenium intermediate. Next, the intermediate could react with chlorobenzene via oxidative addition/reductive elimination sequence to give the mono- and di-arylated product or a second 2-arylpyridine through the similar ortho-cyclometallated process to afford DCCP.

\section{Conclusions}

We developed a simple and recyclable catalytic system for direct arylation using $\mathrm{RuCl}_{3} \cdot x \mathrm{H}_{2} \mathrm{O}$ as a precatalyst, PEG-400 as environmental benign medium and inexpensive aryl chlorides as electrophilic reagents. The reaction met the environment friendly requirements and the strategy was facile and did not require the introduction of any additive or ligand. This system showed high tolerance towards various functional groups. Particularly, selectivity towards mono- or diarylated product could be regulated by varying the reaction conditions. Furthermore, this transformation could be easily scaled up to the gram level with $0.3 \mathrm{~mol} \%$ loading of ruthenium. A reasonable mechanism for this transformation was also proposed.

\section{Experimental}

\subsection{Typical experimental procedure for direct arylation of 2- phenylpyridine under air}

$\mathrm{RuCl}_{3} \cdot x \mathrm{H}_{2} \mathrm{O}(104 \mathrm{mg}, 0.5 \mathrm{mmol})$ and PEG-400 (10 mL) was taken in an oven-dried and clean round-bottom flask. The mixture was stirred at room temperature until $\mathrm{RuCl}_{3} \cdot x \mathrm{H}_{2} \mathrm{O}$ was dispersed to PEG-400 completely. Furthermore, 2-phenylpyridine (1a, 1 mmol), 1-chloro-3-fluorobenzene (2a, $2.3 \mathrm{mmol}$ ), $\mathrm{LiOH} \cdot \mathrm{H}_{2} \mathrm{O}$ (126 mg, $3 \mathrm{mmol}$ ) and PEG-400 (1 mL) containing $\mathrm{RuCl}_{3} \cdot x \mathrm{H}_{2} \mathrm{O}$ (0.05 mmol) were added to a Schlenk tube. The mixture was stirred at $120{ }^{\circ} \mathrm{C}$ under air for $24 \mathrm{~h}$. After cooling to room temperature, the reaction mixture was diluted with $10 \mathrm{~mL}$ 
water. The aqueous layer was extracted with $\mathrm{Et}_{2} \mathrm{O}(20 \mathrm{~mL})$ and EtOAc $(30 \mathrm{~mL})$. The combined organic phase was washed with $\mathrm{H}_{2} \mathrm{O}(20 \mathrm{~mL})$ and brine $(20 \mathrm{~mL})$ and dried with $\mathrm{Na}_{2} \mathrm{SO}_{4}$ and concentrated under reduced pressure. The resulting residue was separated through a flash silica gel column chromatography (petroleum ether/EtOAc $=16: 1$ ) to obtain arylated products $(306 \mathrm{mg}, 95 \%)$. The ratio of mono- to diarylated product was determined by ${ }^{1} \mathrm{H}$ NMR spectroscopy. The arylated products were separated using silica gel column chromatography (petroleum ether/ $\mathrm{CH}_{2} \mathrm{Cl}_{2}=1: 16$ ) to afford target products $3 \mathbf{a a}$ and $\mathbf{4 a a}$, respectively. The product was characterized by ${ }^{1} \mathrm{H}$ NMR and ${ }^{13} \mathrm{C}$ NMR spectroscopy.

\subsection{Recycling experimental procedures}

In a reaction tube, 2-phenylpyridine (1a, $1 \mathrm{mmol})$, 1-chloro-3fluorobenzene (2a, $2.3 \mathrm{mmol}), \mathrm{LiOH} \cdot \mathrm{H}_{2} \mathrm{O}(126 \mathrm{mg}, 3 \mathrm{mmol})$ and PEG-400 $(1 \mathrm{~mL})$ containing $\mathrm{RuCl}_{3} \cdot x \mathrm{H}_{2} \mathrm{O}(0.05 \mathrm{mmol})$ were stirred at $120{ }^{\circ} \mathrm{C}$ under air for $24 \mathrm{~h}$. At the end of the reaction, reaction mixture was cooled to room temperature and extracted by employing $\mathrm{Et}_{2} \mathrm{O}(50 \mathrm{~mL})$. Furthermore, 2-phenylpyridine (1a, $1 \mathrm{mmol}$ ), 1-chloro-3-fluorobenzene (2a, $2.3 \mathrm{mmol}), \mathrm{LiOH} \cdot \mathrm{H}_{2} \mathrm{O}$ (126 mg, $3 \mathrm{mmol}$ ) was added to PEG solution, the reaction and operation were repeated as mentioned above.

\section{Acknowledgements}

We gratefully acknowledge National Natural Science Foundation of China (No. 21572137).

\section{Notes and references}

1 (a) S. A. Bahashwan, A. A. Fayed, A. E.-G. E. Amr, E. M. Flefel and A. Kalmouch, Molecules, 2013, 18, 15051; (b) J. AlvarezBuilla, J. J. Vaquero and J. Barluenga, Mod. Heterocycl. Chem., 2011, 4, 1989; (c) A. Takfaoui, L. Zhao, R. Touzani, P. H. Dixneuf and H. Doucet, Tetrahedron Lett., 2014, 55, 1697; (d) M. Facompre, C. Tardy, C. Bal-Mahieu, P. Colson, C. Perez, I. Manzanares, C. Cuevas and C. Bailly, Cancer Res., 2003, 63, 7392; (e) R. Wilcken, M. O. Zimmermann, A. Lange and A. C. Joerger, J. Med. Chem., 2013, 56, 1363; (f) Y. Segawa, K. Itami and T. Maekawa, Angew. Chem., Int. Ed., 2015, 54, 66.

2 (a) J. C. Garrison and W. J. Youngs, Chem. Rev., 2005, 105, 3978; (b) O. Schuster, L. Yang, H. G. Raubenheimer and M. Albrecht, Chem. Rev., 2009, 109, 3445; (c) Z.-S. Gu, W.-X. Chen and L.-X. Shao, Eur. J. Org. Chem., 2014, 79, 5806; (d) J. J. Concepcion, M. K. Tsa, J. T. Muckerman and T. J. Meyer, J. Am. Chem. Soc., 2010, 132, 1545.

3 (a) N. Marion and S. P. Nolan, Acc. Chem. Res., 2008, 41, 1440;

(b) J. Hassan, M. Sevignon, C. Gozzi, E. Schulz and M. Lemaire, Chem. Rev., 2002, 102, 1359; (c) L. Ackermann, J. H. Spatz, C. J. Gschrei, R. Born and A. Althammer, Angew. Chem., Int. Ed., 2006, 118, 7789; (d) L. Ackermann, R. Born, J. H. Spatz and D. Meyer, Angew. Chem., Int. Ed., 2005, 117, 7382 .
4 For recent reviews on direct arylation of heterocycles $(a)$ P. B. Arockiam, C. Bruneau and P. H. Dixneuf, Chem. Rev., 2012, 112, 5879; (b) C.-L. Sun, B.-J. Li and Z.-J. Shi, Chem. Rev., 2011, 111, 1293; (c) L. Ackermann, R. Vicente and A. R. Kapdi, Angew. Chem., Int. Ed., 2009, 48, 9792; (d) Y. Liang and S. F. Wnuk, Molecules, 2015, 20, 4874; (e) M. He, J.-F. Soulé and H. Doucet, ChemCatChem, 2014, 6, 1824.

5 (a) L. Ackermann, J. Org. Chem., 2014, 79, 8948; (b) M.-Z. Lu, P. Lu, Y.-H. Xu and T.-P. Loh, Org. Lett., 2014, 16, 2614; (c) W. Hagui, N. Besbes, E. Srasra, J.-F. Soulé and H. Doucet, RSC Adv., 2016, 6, 17110; (d) H. Xu, M. Shang, H.-X. Dai and J.-Q. Yu, Org. Lett., 2015, 17, 3830; (e) P.-X. Shen, X.-C. Wang, P. Wang, R.-Y. Zhu and J.-Q. Yu, J. Am. Chem. Soc., 2015, 137, 11574; (f) L. Ackermann, J. Pospech and H. K. Potukuchi, Org. Lett., 2012, 14, 2146.

6 (a) C. G. Baumann, S. D. Ornellas, J. P. Reeds, T. E. Storr, T. J. Williams and I. J. S. Fairlamb, Tetrahedron, 2014, 70, 6174; (b) T.-H. Park, A. J. Hickman, K. Koh, S. Martin, A. G. Wong-Foy, M. S. Sanford and A. J. Matzger, J. Am. Chem. Soc., 2011, 133, 20138; (c) C. P. Perumgani, S. P. Parvathaneni, B. Kodicherla, S. Keesara and M. R. Mandapati, Inorg. Chim. Acta, 2017, 455, 105; (d) L.-C. Lee, J. He, J.-Q. Yu and C. W. Jones, ACS Catal., 2016, 6, 5245; (e) D. E. Bergbreiter, P. L. Osburn and Y.-S. Liu, J. Am. Chem. Soc., 1999, 121, 9531; (f) F. Liu, C. Liu, W. Kong, C. Qi, A. Zheng and S. Dai, Green Chem., 2016, 18, 6536.

7 (a) F. Pozgan and P. H. Dixneuf, Adv. Synth. Catal., 2009, 351, 1737; (b) S. Oi, S. Fukita, N. Hirata, N. Watanuki, S. Miyano and Y. Inoue, Org. Lett., 2001, 3, 2579; (c) L. Ackermann, R. Vicente and A. Althammer, Org. Lett., 2008, 10, 2299; (d) B. Li, C. B. Bheeter, C. Darcel and P. H. Dixneuf, Top. Catal., 2014, 57, 833; (e) S. Rajkumar, S. Karthik and T. Gandhi, J. Org. Chem., 2015, 80, 5532.

8 (a) C. Fischmeister and H. Doucet, Green Chem., 2011, 13, 741; (b) A. Hfaiedh, K. Yuan, H. B. Ammar, B. B. Hassine, J.-F. Soulé and H. Doucet, ChemSusChem, 2015, 8, 1794; (c) P. Arockiam, V. Poirier, C. Fischmeister, C. Bruneau and P. H. Dixneuf, Green Chem., 2009, 11, 1871; (d) W. Muramatsu, K. Nakanoa and C.-J. Li, Org. Biomol. Chem., 2014, 12, 2189.

9 (a) H. Gong, H. Zeng, F. Zhou and C.-J. Li, Angew. Chem., Int. Ed., 2015, 54, 5718; (b) Y.-B. Huang, M. Shen, X. Wang, P. Huang, R. Chen, Z.-J. Lin and R. Cao, J. Catal., 2016, 333, 1; (c) P. B. Arockiam, C. Fischmeister, C. Bruneau and P. H. Dixneuf, Angew. Chem., Int. Ed., 2010, 49, 6629; (d) Z. Xu, T. Yang, X. Lin, J. D. Elliott and F. Ren, Tetrahedron Lett., 2015, 56, 475; (e) P. B. Arockiam, C. Fischmeister, C. Bruneau and P. H. Dixneuf, Green Chem., 2013, 15, 67.

10 (a) G. C. Reddy, P. Balasubramanyam, N. Salvanna and B. Das, Eur. J. Org. Chem., 2012, 3, 471; (b) Q. Zhang, J.-X. Chen, W.-X. Gao, J.-C. Ding and H.-Y. Wu, Appl. Organomet. Chem., 2010, 24, 809; (c) S. Mishra, B. Naskar and R. Ghosh, Tetrahedron Lett., 2012, 53, 5483; (d) N. M. Smith, C. L. Raston, C. B. Smith and A. N. Sobolev, Green Chem., 2007, 9, 1185; (e) S. Verma, S. L. Jain and B. Sain, Beilstein J. Org. Chem., 2011, 7, 1334; (f) S. L. Jain, 
S. Singhal and B. Sain, Green Chem., 2007, 9, 740; $(g)$ N. Kavitha, G. Sukumar, V. P. Kumar, P. S. Mainkar and S. Chandrasekhar, Tetrahedron Lett., 2013, 54, 4198; (h) S. H. Kim, H. S. Lee, S. H. Kim and J. N. Kim, Tetrahedron Lett., 2008, 49, 5863.

11 (a) L. Ackermann and R. Vicente, Org. Lett., 2009, 11, 4922; (b) M.-A. Hiebel, Y. Fall, M.-C. Scherrmann and S. BerteinaRaboin, Eur. J. Org. Chem., 2014, 21, 4643.

12 (a) Y. Yang, X. Qiu, Y. Zhao, Y. Mu and Z. Shi, J. Am. Chem. Soc., 2016, 138, 495; (b) Z. Liang, R. Feng, H. Yin and Y. Zhang, Org. Lett., 2013, 15, 4544; (c) B. N. Laforteza, K. S. L. Chan and J.-Q. Yu, Angew. Chem., Int. Ed., 2015, 54, 11143; (d) J. Hubrich, T. Himmler, L. Rodefeld and L. Ackermann, Adv. Synth. Catal., 2015, 357, 474.

13 W. Li, Y. Guo and P. Zhang, J. Phys. Chem. C, 2010, 114, 6413. 14 I. Ozdemir, S. Demir, B. Cetinkaya, C. Gourlaouen, F. Maseras, C. Bruneau and P. H. Dixneuf, J. Am. Chem. Soc., 2008, 130, 1156.

15 L. Ackermann, Org. Lett., 2005, 7, 3123.

16 J. Zhang, Q. Yang, Z. Zhu, M. L. Yuan, H. Y. Fu, X. L. Zheng, H. Chen and R. X. Li, Eur. J. Org. Chem., 2012, 34, 6702.
17 S. Sabater, J. A. Mata and E. Peris, Organometallics, 2012, 31, 6450.

18 (a) D. Kalyani, N. R. Deprez, L. V. Desai and M. S. Sanford, J. Am. Chem. Soc., 2005, 127, 7330; (b) L. Ackermann, R. Vicente, H. K. Potukuchi and V. Pirovano, Org. Lett., 2010, 12, 5032; (c) D. Zell, S. Warratz, D. Gelman, S. J. Garden and L. Ackermann, Chem.-Eur. J., 2016, 22, 1248.

19 L. Zhang, L. Wang, X.-Y. Ma, R.-X. Li and X.-J. Li, Catal. Commun., 2007, 8, 2238.

20 (a) L. Ackermann, N. Hofmann and R. Vicente, Org. Lett., 2011, 13, 1875; (b) E. Diers, N. Y. P. Kumar, T. Mejuch, I. Marek and L. Ackermann, Tetrahedron, 2013, 69, 4445.

21 (a) K. L. Hull, E. L. Lanni and M. S. Sanford, J. Am. Chem. Soc., 2006, 128, 14047; (b) X. Guo, G. Deng and C.-J. Li, Adv. Synth. Catal., 2009, 351, 2071; (c) X. Chen, G. Dobereiner, X.-S. Hao, R. Giri, N. Maugel and J.-Q. Yu, Tetrahedron, 2009, 65, 3085.

22 (a) L. Ackermann, Chem. Rev., 2011, 111, 1315; (b) D. L. Davies, S. M. A. Donald and S. A. Macgregor, J. Am. Chem. Soc., 2005, 127, 13754; (c) J. Hubrich, T. Himmler, L. Rodefeld and L. Ackermann, ACS Catal., 2015, 5, 4089; (d) L. Ackermann, Org. Process Res. Dev., 2015, 19, 260. 